\title{
The Risk of Myocardial Infarction Associated With Antihypertensive Drug Therapies
}

\author{
Bruce M Psaty, MD, PhD, Susan R Heckbert, MD, PhD, Thomas D Koepsell, MD, MPH, David S Siscovick, MD, MPH, \\ Trivellore E Raghunathan, PhD, Noel S Weiss, MD, DrPH, Frits R Rosendaal, MD, Rozenn N Lemaitre, PhD MPH, \\ Nicholas L Smith, MPH, Patricia W Wahl, PhD, Edward H Wagner, MD, MPH, Curt D Furberg, MD, PhD
}

Objective.-To assess the associatıon between first myocardial infarctıon and the use of antihypertensive agents.

Design and Setting.-We conducted a populatıon-based case-control study among enrollees of the Group Health Cooperative of Puget Sound (GHC).

Patients and Methods.-Cases were hypertensive patients who sustanned a first fatal or nonfatal myocardial infarctıon from 1986 through 1993 among women and from 1989 through 1993 among men. Controls were a stratfied random sample of hypertensive $\mathrm{GHC}$ enrollees, frequency matched to the cases on age, sex, and calendar year. All 623 cases and 2032 controls had pharmacologically treated hypertension. Data collection included a review of the ambulatory medical record and a brief telephone interview of consenting survivors. Antihypertensive therapy was assessed using the GHC's computerized pharmacy database.

Results. - The first analysis included only the 335 cases and 1395 controls initially free of cardıovascular disease. Compared with users of diuretics alone, the adjusted risk ratio of myocardial infarction was increased by about $60 \%$ among users of calclum channel blockers with or without diuretics (risk ratio $=1.62 ; 95 \%$ confidence interval [Cl], 1.11 to $2.34 ; P=.01$ ). The second analysis was restricted to 384 cases and 1108 controls who were taking either a calcium channel blocker or a $\beta$-blocker. Among these subjects, the use of calcium channel blockers compared with $\beta$-blockers was associated with about a $60 \%$ increase in the adjusted risk of myocardial infarctıon (rısk ratio $=1.57 ; 95 \% \mathrm{Cl}, 1.21$ to $2.04 ; P<.001$ ). While hıgh doses of $\beta$-blockers were associated with a decreased risk of myocardial infarction (trend $P=.04$ ), high doses of calcium channel blockers were associated with an increased risk (trend $P<.01$ ).

Conclusions.-In this study of hypertensive patients, the use of short-acting calcium channel blockers, especially in high doses, was associated with an increased risk of myocardıal infarction. Ongoing large-scale clinical trals will assess the effect of various antihypertensive therapies, Including calcum channel blockers, on several important cardiovascular end points. Until these results are available, the findings of this study support the current guidelines from the Joint National Committee on the Detection, Evaluation and Treatment of High Blood Pressure that recommend diuretıcs and $\beta$-blockers as first-line agents unless contraindicated, unacceptable, or not tolerated.

$(J A M A \quad 1995,274020-(325)$

\footnotetext{
From the Cardiovascular Health Research Unit the Departments of Medicine (Drs Psaty Koepsell and Siscovick) Epidemlology (Drs Psaly Heckbert Koepsell Siscovick Weiss Lemattre and Smith) Bioslatıs tics (Dr Wahi) and Hoalth Sorvices (Drs Psaly Koepsell and Wagner) Universily of Washıngton Scattlo Survey Research Centcr Inst ILte for Soclal Research Unversity of Michigan Ann Arbor (Dr Raghunathan) Department of Clinical Epidemology Universily Hos pital Leiden the Netheriands (Dr Rosendaal) the Conter for Health Studies Group Hoalth Cooperative of Pugel Sound Scattlo Wash (Dr Wagner) and Depart ment of Public Health Sciences Bowman Gray School of Medicine Winston Salom NC (Or Furberg)

Reprints requests to Cardiovascular Hcalth Re search Unit Mclropolitan Park East Tower Sulte 1360 1730 Munor Ave Seattlo WA 98101 (Dr Psaly)
}

THE JOINT National Committee (JNC) on the Detection, Evaluation and Treatment of High Blood Pressure currently recommencls diuretics or $\beta$-blockers as first-line drug therapy for hypertension. ${ }^{1}$ Low-dose diuretic therapy is not only safe $^{2}$ but also effective in preventing stroke, myocardial infarction, congestive heart failure, and total mortality. 5

During the $1980 \mathrm{~s}$, calcium channel blockers and angiotensin-converting enzyme (ACE) inhibitor's were approved for the treatment of hypertension based on the surrogate end point of lowering blood pressure. In the last decade, their use has increased dramatically, ${ }^{6}$ although the clinical trials evaluating these agents against end points such as left ventricular mass " and quality of life ${ }^{\prime 11}$ do not suggest a major advantage. In terms of their effect on major-disease end points such as myocardial infarction and mortality, calcium channel blockers and $\mathrm{ACE}$

For editorial comment see p 654 .

inhibitor's have been evaluated only in the secondary prevention trials of patients with coronary disease ${ }^{11}$ ' or congestive heart failure. ${ }^{141}$. The results of the secondary prevention randomized clinical trials comparing calcium channel blockers with placebo suggest the possibility of harm, especially for the short-acting dihydropyridine class. ${ }^{121} 1^{1617}$ In one recent meta-analysis," mortality was significantly increased, and there was a strong linear relationship between the dose of nifedipine and the risk of mortality $(P=.01)$. Whether similar adverse effects appear among patients with high blood pressure remains untested although several clinical trials are in progress..$^{41}$

To assess the association between antihypertensive therapy and the incidence of myocardial infarction, we conducted a population-based case-control study. Based on the results of the secondary prevention trials, " we had hypothesized the possibility of an adverse effect of calcium channel blockers.

\section{METHODS}

\section{Setting}

The setting was the Group Health Cooperative of Puget Sound (GHC), Seattle, Wash. The GHC recommendations concerning antihypertensive therapy follow the JNC, ${ }^{12}$ and the guidelines of the fourth report of the JNC (1988 through 1993), in effect during most of the study period, recommended calcium channel blockers as one of the initial therapies for hypertension. $^{22}$ While all major classes of anti- 
hypertensive agents were well represented at the GHC, only the short-acting formulations of the calcium channel blockers were available for routine use.

\section{Identification of Cases and Controls}

Cases were the GHC enrollees, aged 30 to 79 years, who had pharmacologically treated hypertension and who were diagnosed with an incident fatal or nonfatal myocardial infarction during July 1989 through December 1993. A companion study of hormone replacement therapy ${ }^{2}$ used identical methods and allowed us to include 208 female hypertensive controls and 112 cases diagnosed during July 1986 through June 1989 . We identified potential cases from (1) the computerized discharge abstracts for the two GHC hospitals; (2) the bills for out-of-plan services provided by non-GHC physicians and health care facilities; and (3) the results of a computerized match between the GHC enrollment files and the Washington State death registry files. We have used these methods in previous studies. ${ }^{23} 25$ In a blinded validation study, ${ }^{2 ;}$ the estimated completeness of case ascertainment was high $(95 \%)$, and $97 \%$ of eligible cases met standard criteria for definite or probable myocardial infarction.

Controls were a stratified random sample of GHC enrollees with pharmacologically treated hypertension, and they were frequency matched to the cases by sex, age (within decade), and calendar year at a ratio of between $2: 1$ and $3: 1$. Controls met the same eligibility criteria as the cases, but they did not have a myocardial infarction.

\section{Index Dates and Eligibility}

All subjects had an index date. For the hospitalized cases, the index date was the date of admission for the first myocardial infarction; for the out-of-hospital fatal cases, the index date was the date of death; and for the controls, the index date was a computer-generated random date within the calendar year for which they had been sampled as controls. For all subjects, we collected information about eligibility and risk factor data available only before the index date. We excluded subjects (1) who were enrollees for less than 1 year or who had had fewer than four visits before their index dates; (2) who did not have a diagnosis of hypertension in their medical record; (3) who had had a prior myocardial infarction; and (4) whose myocardial infarction was a complication of a procedure or surgery.

\section{Data Collection and Definition of Antihypertensive Drug Use}

Data collection included a review of the GHC ambulatory medical record and a telephone interview of consenting survi- vors. Based on the medical record, trained research assistants determined eligibility and collected information about traditional risk factors for coronary heart disease, such as blood pressure, smoking, angina, diabetes, and cholesterol. The telephone interview sought similar information about risk factors, such as smoking status, physical activity, education, and race. It was not practicable to blind research assistants to case-control status. Although they knew the study involved hypertension, they were not told about the hypotheses related to specific antihypertensive drug therapies.

The GHC computerized pharmacy database was used to assess antihypertensive drug therapies. Each pharmacy record includes the drug type and dose, quantity dispensed, date, and dosing instructions. When the dosing instructions were missing from the pharmacy data, we used the instructions available in the medical record. For determining use on a particular date, we searched the pharmacy data for the antihypertensive drug prescription immediately preceding that date: when a subject, who was assumed to be at least $80 \%$ compliant, received enough pills to last until the date of interest, that person was counted as a potential current user on that date. This process was repeated to determine use at 30 and 60 days before the index date.

Because of concerns about the potential confounding effects of recently starting drug therapies, a current user was defined as a subject who was a user not only on the index date, but also for at least 30 days before the index date. This requirement for a minimum duration of use permitted us to exclude recent starters, whose drug course was prescribed within 30 days of the index date. In preliminary analyses, recent starting of $\beta$-blockers and calcium channel blockers was strongly associated with the risk of myocardial infarction (risk ratio $=2.68$ and 2.52 , respectively; $P<.01$ ). The recent starting of these drugs, which are also indicated for the treatment of angina, is likely to be a marker of suspected coronary disease, ${ }^{26}$ and inclucling recent starters as if they had been regular users might have introduced bias through confounding by the secondary indication of angina.

In dose-response analyses, we used the distribution of total daily doses to define three groups of approximately equal size. Subjects taking the modal dose comprised the middle group, and subjects taking more or less than the modal dose formed the other two groups. The modal daily doses were $30 \mathrm{mg}$ for nifedipine, $180 \mathrm{mg}$ for diltiazem hydrochloride, $240 \mathrm{mg}$ for verapamil hydrochloride, $80 \mathrm{mg}$ for propranolol hydrochloride, $100 \mathrm{mg}$ for metoprolol tartrate,
$80 \mathrm{mg}$ for nadolol, and $50 \mathrm{mg}$ for atenolol. In terms of their effects on blood pressure, these doses are approximately equivalent to one another. ${ }^{24,27}$

\section{Statistical Analysis}

Data were complete for case-control status and the variables defining current drug use. Medical conditions were uniformly available, while recent blood pressures and laboratory values were available for $96.2 \%$ to $100 \%$ of the subjects. For continuous data with less than $5 \%$ missing data, we imputed the case-control and sexspecific means. In preliminary analyses of categorical data, the agreement between medical-record and self-reported measures was good to excellent. Self-reported data, if available, were used; if not, then data from the medical record were used as covariates in analyses. For these combined categorical variables, data were missing on race $(5.1 \%)$, smoking $(1.3 \%)$, and physical activity (7.2\%). In sensitivity analyses, coding of missing data as one value or another value for the categorical variables had trivial effects on the results. Data were also missing on cholesterol $(8.5 \%)$, duration of hypertension $(6.9 \%)$, and pretreatment blood pressure (33\%), largely for subjects who had begun antihypertensive therapy before joining the GHC. For these continuous covariates, we used linear regression to estimate the missing data, and in sensitivity analyses, the confounding effects of covariates were small and similar to those seen in the analysis of subjects with complete data.

All statistical tests were two tailed. We used stratification and logistic regression to control for potential confounding factors and to estimate risk ratios. 28,29

To assess the association of antihypertensive drug therapies with myocardial infarction, we used two approaches. In the first, we excluded subjects with clinical cardiovascular disease (CVD), defined as possible, probable, or definite diagnoses of angina, stroke, or claudication; history of coronary angioplasty, coronary bypass surgery, peripheral vascular surgery, or carotid endarterectomy; and receipt of a prescription for nitroglycerin within 90 days of the index date. (Subjects with congestive heart failure or a previous myocardial infarction were not eligible.) Among subjects free of clinical CVD (other than hypertension), single-drug users of diuretics served as the reference group, and we created indicator variables for each of the other major single-drug and twodrug combinations. In the second approach, subjects were included only if they were users of either $\beta$-blockers or calcium channel blockers. In these analyses, which were stratified on the presence or absence of CVD, users of $\beta$-blockers served as the reference group. 
Table 1 - Characterıstıcs of Cases and Controls'

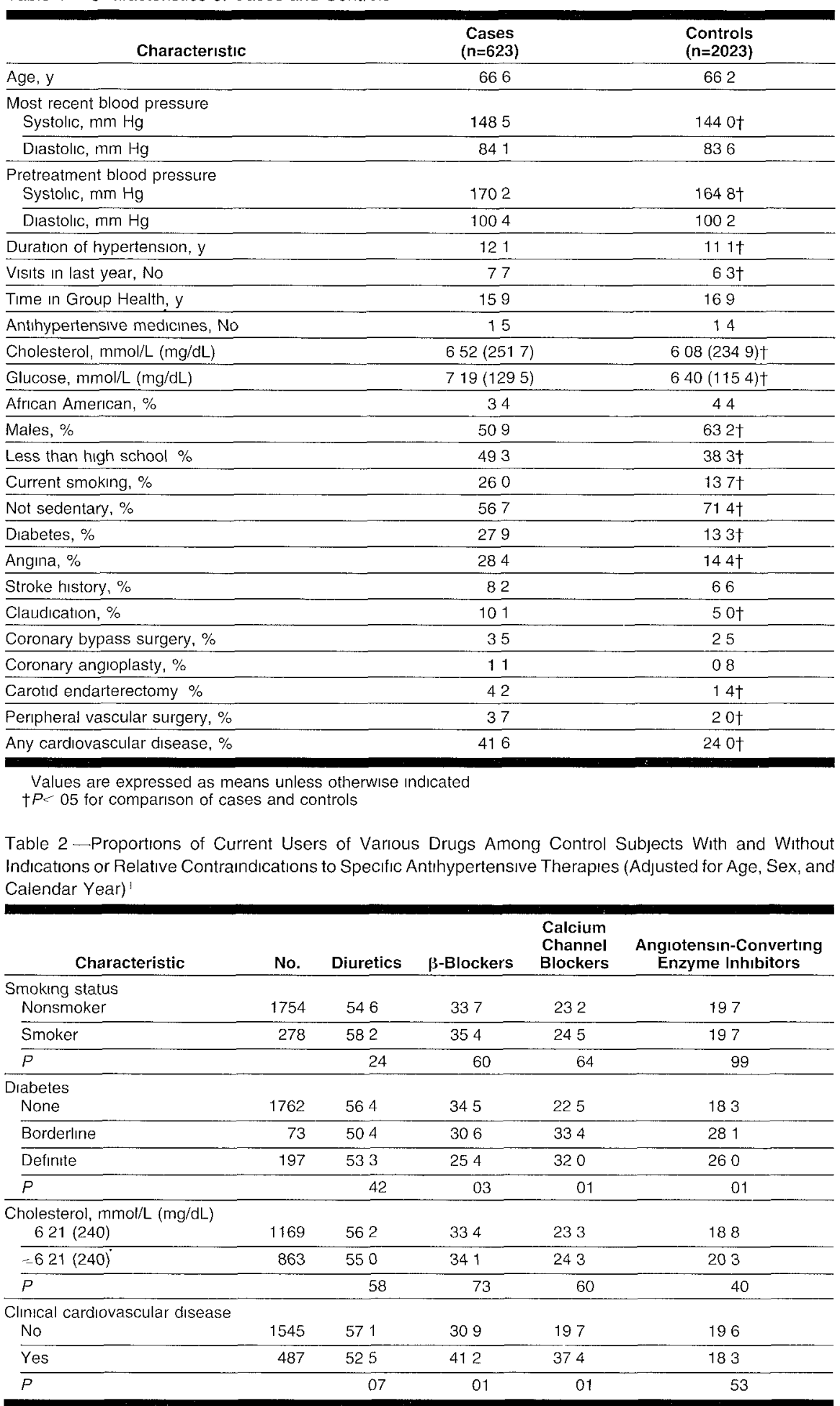

'Percentages are "row' percentages for instance, $546 \%$ of nonsmokers used diuretics, $582 \%$ of smokers used diuretics, and the difference between the two proportions was not statistically significant $(P=24)$

\section{RESULTS}

During the study period, 930 hyper" tensive patients were hospitalized for or clied out-of-hospital fiom al first myocardial infarction. We also identified 2598 population-baser controls. In this analysis, we excluded (1) 20 cases and 99 con- trols who refused participation; (2) 103 cases and 113 controls who had congestive heart failure; (3) 150 cases and 331 controls who were not sufficiently compliant with their medications to be classified as current users of an antihypertensive merlication; and (4) 34 cases and 23 controls who were recent starter's of $\beta$-blockers or calcium channel blockers. As a result, this study included 623 cases and 2032 controls with pharmacologically treated hypertension.

The time enrolled in the GHC, pretreatment diastolic blood pressures, and recent diastolic blood pressures (Table 1) were similar in cases and controls. Cases differed from controls for a number of traditional risk factors, including systolic blood pressure (Table 1).

Antihypertensive therapies have a variety of adverse effects and relative contraindications that may affect the choice of therapy. $\beta$-Blockers are relatively contraindicated in patients with reactive airway disease, which is often associated with smoking. In short-term studies, ${ }^{3}$ diuretics and $\beta$-blockers reportedly have adverse effects on lipid levels. Among controls (Table 2), the use of $\beta$-blockers was similar in smoker's $(35.4 \%)$ and nonsmokers $(33.7 \%)$, and the use of all antihypertensive agents was similar among subjects with and without elevated levels of cholesterol. The use of both calcium channel blockers and $\beta$-blocker's was, however, strongly associated with the secondary indication of preexisting CVD, primarily angina $(P<.001)$.

The initial analysis was restricted to the 335 cases and 1395 controls who were free of clinical CVD and who were taking either one of the major single drugs or one of the major two-drug combinations (Figure 1). The levels of treated systolic and diastolic blood pressure were comparable among the nune drug groups. The risk ratios in Figure 1 were adjusted for age, sex, calendar year, smoking, diabetes, pretreatment systolic blood pressure, duration of hypertension, education, and physical activity. Compared with the use of diuretics alone, the use of calcium channel blockers, with or without diuretics, was associated with a $58 \%$ to $70 \%$ increase in the risk ratio for myocarlial infarction (Figure 1). Treating calcium channel blocker's as a single variable, with or without diuretics, yielded an adjusted risk ratio of 1.62 (95\% confidence interval [CI], 1.11 to $2.34 ; P=.01)$.

Figure 2 represents the association of myocardial infarction with the dose of calcium channel blockers among subjects free of clinical CVD. As dose increased, so did the level of risk even after adjustment for potential confounding factors. The tests for trend in dose of calcium channel blockers, both alone and in combination with diuretics, wel'e highly significant $(P<.01)$.

The second analysis was restricted to the 384 cases and 1108 controls who were taking either a calcium channel blocker $\mathrm{or}^{\circ}$ a $\beta$-blocker. After adjustment, the use of calcium channel blockers compared with $\beta$-blockers was associated with an in- 
creased risk of myocardial infarction both among subjects with CVD (risk ratio=1.61; 95\% CI, 1.07 to 2.42) and among those without CVD (risk ratio $=1.60 ; 95 \% \mathrm{CI}$, 1.12 to 2.27). For all hypertensive patients combined-those with and without CVD-the adjusted risk of myocardial infarction associated with the use of calcium channel blockers compared with $\beta$-blockers was 1.57 (95\% CI, 1.21 to 2.04; $P<.001)$. The adjusted risk ratios for individual calcium channel blockers were similar: for nifedipine, 1.31 (95\% CI, 0.85 to $2.01 ; P=.22)$; for diltiazem, $1.63(95 \% \mathrm{CI}$, 1.06 to $2.50 ; P=.03)$; and for verapamil, 1.61 (95\% CI, 1.19 to $2.17 ; P<.01$ ). These risk ratios did not differ significantly from one another.

Figure 3 represents the results of the dose-response analysis for the comparison of calcium channel blockers and $\beta$-blockers. The findings were similar among hypertensive patients with and without CVD. Low-dose users of $\beta$-blockers served as the reference group. As the dose of $\beta$-blockers increased, the adjusted risk ratios decreased to 0.88 and 0.73 for the medium-dose and high-dose $\beta$-blockers groups, respectively. In contrast, as the dose of calcium channel blockers increased, so did the adjusted risk ratios for myocardial infarction-from 1.13 to 1.42 and up to 1.81 for the three dosage groups. Not only were these dose-response trends in the opposite direction, but the tests for trend were also both statistically significant $(P<.05)$. Dose-response analyses for the individual drugs showed a similar pattern among subjects with and without CVD.

The risk ratios of myocardial infarction associated with the use of calcium channel blockers compared with $\beta$-blockers were similar in a variety of subgroups: 1.72 for age younger than the sex-specific median vs 1.53 for age greater than or equal to the median; 1.72 for nondiabetics vs 1.08 for diabetics; 1.51 for women vs 1.65 for men; 1.53 for nonsmokers vs 1.86 for current smokers; and 1.64 for the 80th percentile or less of creatinine vs 1.39 for greater than the 80 th percentile. The $P$ values for the statistical test of a difference between the pairs of risk ratios were 0.41 for age, 0.28 for diabetes, 0.44 for sex, 0.95 for smoking status, and 0.46 for renal function.

In other analyses, adjustment for additional factors-cholesterol, glucose, potassium, height and weight, family history, self-reported aspirin use, income, race, employment, occupation, marital status, pretreatment diastolic blood pressure, treated systolic blood pressure, and treated diastolic blood pressure-had trivial effects on the findings. The use of various alternative defini-

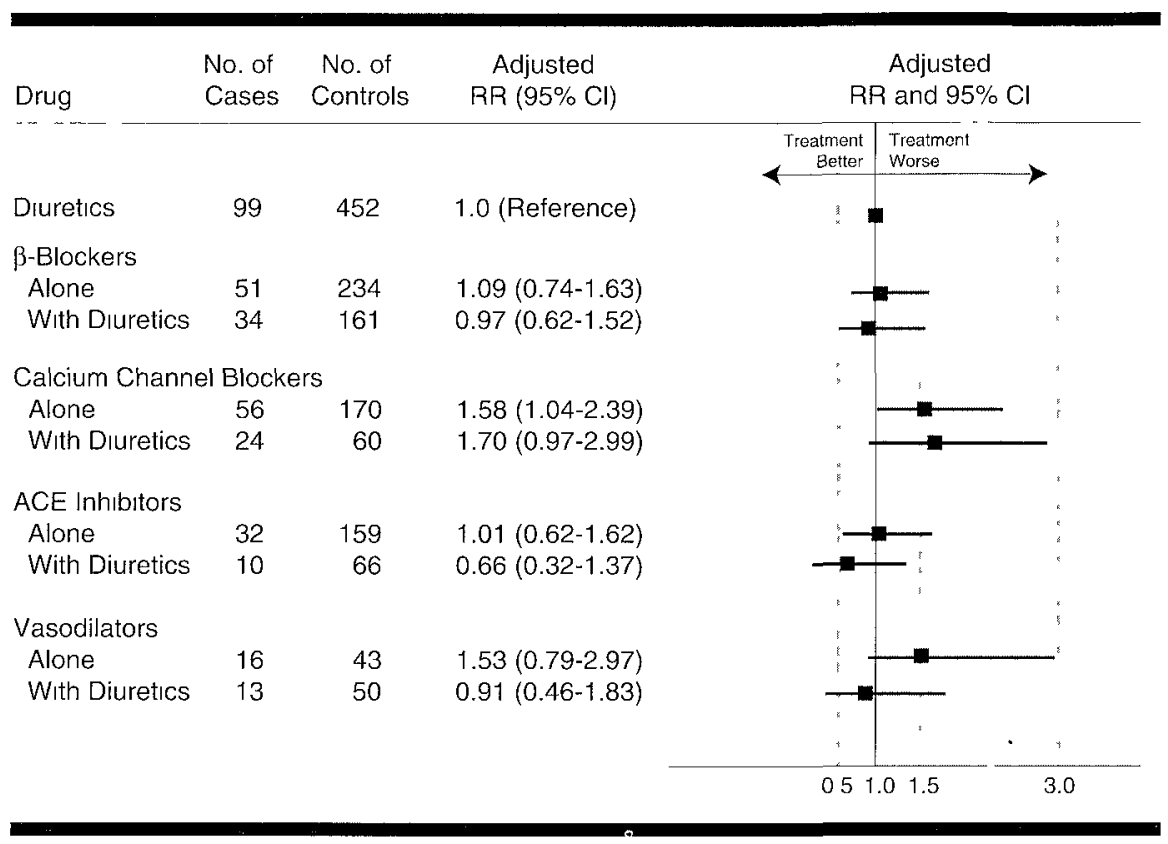

Figure 1 -..Associatıon between myocardial infarction and antihypertensıve drug therapies among subjects without any clinical cardıovascular disease. RR indıcates risk ratıo (boxes); Cl, confidence interval (cross bars); ACE, angıotensın-converting enzyme. The RRs were all adjusted for age, sex, calendar year, smokıng, diabetes, pretreatment systolic blood pressure, duratıon of hypertension, physical activity, and educatıon.

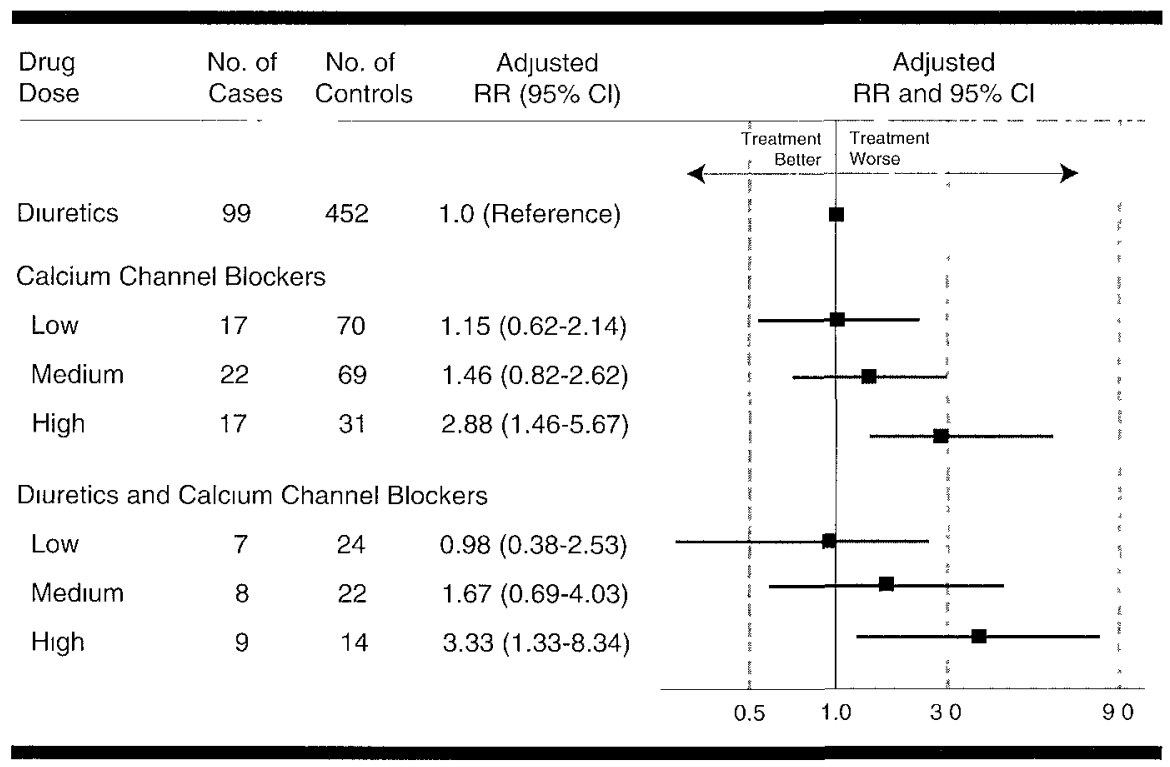

Figure $2-$ Association between myocardial infarction and dose of calcium channel blockers among subjects without any clinical cardıovascular disease. RR ındıcates risk ratıo (boxes); $\mathrm{Cl}$, confidence interval (cross bars) All RRs were adjusted for the same factors listed in the legend to Figure 1. $P$ values for the test for trend were .003 among single-drug users of calcium channel blockers and .008 among users of diuretics plus calcium channel blockers. The RRs in the figure are on a logarithmic scale.

tions for CVD also affected the results in only trivial ways. Neither the division of diuretic users into those who did and did not also use a potassium-sparing agent nor the division of diuretic users into dosage groups had any effect on the results. Case fatality rates were similar in subjects taking calcium channel blockers compared with subjects taking $\beta$-blockers (risk ratio $=0.95 ; 95 \% \mathrm{CI}, 0.51$ to 1.76 ).

\section{COMMENT}

In this population-based case-control study, the use of calcium channel blockers as antihypertensive therapy was consistently associated with about a $60 \%$ increase in the risk ratio for incident myocardial infarction. The association persisted after we controlled for many known risk factors for myocardial infarction: it was independent of the reference group 


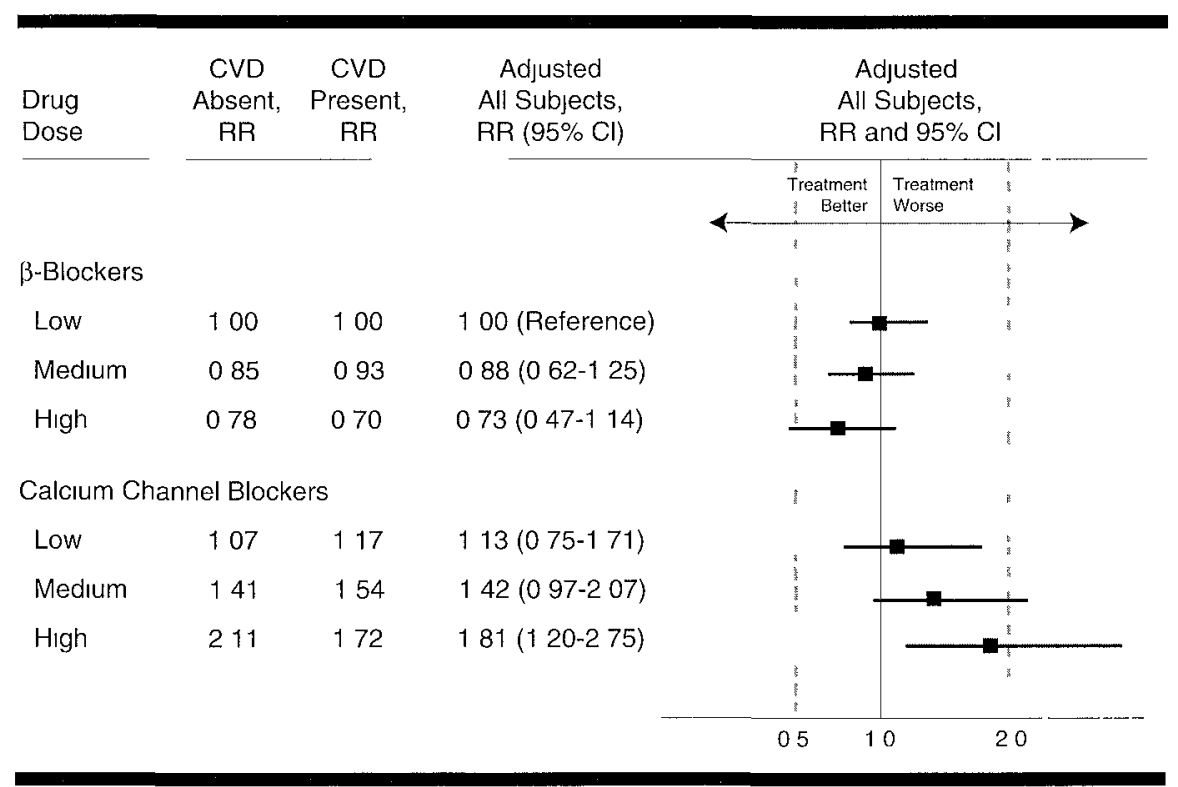

Figure 3-Association between myocardial infarction and use of calcium channel blockers compared with the low-dose users of $\beta$-blockers dose-response analysis stratified by the presence or absence of clinical cardıovascular disease (CVD) RR indicates risk ratıo (boxes), $\mathrm{Cl}$, confidence interval (cross bars) Among subjects without CVD, the RRs were adjusted for the factors listed in the legend of Figure 1 Among subjects with CVD and among all subjects, the RR was adjusted not only for age, sex, calendar year smoking, drabetes, pretreatment systolic blood pressure, duration of hypertension physical activity, and education, but also for the clinıcal CVD characteristıcs of angina, stroke, claudicatıon, coronary angıoplasty, coronary bypass surgery, peripheral vascular surgery, carotid endarterectomy, and recent use of nitroglycerin For all subjects, $P$ values for the tests for trend were 035 for $\beta$-blockers and 003 for calcium channel blockers

(Figures 1 through 3); it was specific to calcium channel blockers but not $\beta$-blockers or ACE inhibitors, either alone or in combination with diuretics; it was consistent across multiple subgroups; and it was most pronounced among subjects taking high doses of calcium channel blockers. The dose-response findings were not only statistically significant, but they also went in opposite directions for $\beta$-blockers and calcium channel blockers (Figure 3 ). The dose-response findings for calcium channel blockers and myocardial infarction in this study are similar to the dose-response findings for short-acting nifedipine and mortality in a meta-analysis of secondary prevention trials. ${ }^{13}$

The strengths of this observational study include the use of population-based cases and controls, the completeness of case identification, the validation of case diagnosis, the comparable ascertainment of potential confounding factors, and the use of the GHC pharmacy database to assess antihypertensive therapy in a comparable and unbiased fashion. Restriction, stratification, and adjustment were used to minimize the possibility of confounding. All subjects, moreover, were enrollees of a health maintenance organization and thus had similar access to health care.

Well-designed case-control studies can complement the clinical trials. ${ }^{2}$ In part because a large number of alternative therapies are available and commonly used, antihypertensive therapy is well suited to an outcome evaluation by observational methods. The high degree of similarity in treatment regimens between controls with and without various clinical characteristics (Table 2) not only minimizes the possibility of important confounding by those characteristics, but also provides some assurance of the validity of the adjusted comparisons. As an observational study, the case-control design also has several limitations. First, physicians and patients selected antihypertensive therapy, and this self-selection may have introduced bias. Second, there may have been unknown or unmeasured confounding factors for which adjustment was not possible. Third, measurement error in the assessment or estimation of covariates and their severity may have resulted in incomplete adjustment and residual confounding. For instance, despite adjustment for potential confounding factors, it is difficult to exclude the possibility that among subjects free of clinical CVD (Figure 2), higher doses of calcium channel blockers were simply a marker for more severe hypertension. Clinical trials, which are not subject to these limitations, are important because they can assess the overall risk or benefit of a therapy in terms of a variety of important cardiovascular outcomes-not only myocardial infarction but also stroke, congestive heart failure, and renal disease.

Ideally, practitioners would like to base clinical decisions on the results of randomized clinical trials that include major disease end points. Currently, approval by the Food and Drug Administration requires evidence of efficacy measured solely in terms of the effect of antihypertensive agents on a surrogate end point-the level of blood pressure. Clinical trial data for the long-term safety and efficacy of calcium channel blockers are lacking in patients with high blood pressure.

Recent conference reports summarizing the results of two randomized clinical trials suggest the possibility of harm associated with the use of calcium channel blockers in hypertensive patients. ${ }^{\prime 1}$ i2 In a clinical trial designed to assess the effects of antihypertensive therapy on carotid atherosclerosis, ${ }^{31}$ '" subjects randomized to isradipine and followed for 3 years had a higher rate of cardiovascular events than those randomized to a hydrochlorothiazide (risk ratio $=1.78 ; 95 \%$ CI, 0.94 to $3.38 ; P=.07$ ). In another clinical trial reported in Japan, ;2 1017 hypertensive patients randomized to a calcuum channel blocker had a significantly higher incidence of cerebrovascular events than the 1025 patients randomized to an ACE inhibitor (risk ratio=3.0; 95\% CI, 1.1 to $8.3 ; P=.02$ ). This finding occurred despite a greater reduction in the level of blood pressure among those randomized to the calcium channel blocker. These clinical trial data illustrate the crucial point that because drugs have multiple effects, the use of blood pressure may not be adequate as a surrogate for the effect of antihypertensive therapies on major disease end points.

There are several plausible explanations for an adver'se effect of the calcium channel blockers seen in these studies ${ }^{13}$ : (1) negative inotropic effects; (2) proarrhythmic effects; (3) prohemorrhagic effects ${ }^{34}$; (4) proischemic effects from the coronary steal phenomenon ${ }^{35}$; and (5) for short-acting dihydropyridines, a reflex increase in sympathetic activity," one which could theoretically produce plaque rupture. ${ }^{37}$ Multiple-day dosing required of short-acting agents may also lead to poorer compliance and control of blood pressure. With the exception of the prevention of restenosis after angioplasty," the finding of an adverse effect of calcium channel blockers in our study is consistent with other recent reports of the adverse effects of the extensively studied short-acting dihydropyridine calcium channel blockers. 11 1, 16173132

For nondihydropyridine calcium channel blockers, ${ }^{12}$ the secondary prevention trials have shown no effect on mortality (risk ratio $=0.95 ; 95 \%$ CI, 0.82 to 1.09 ) and a reduction in reinfarction (risk ratio $=0.79 ; 95 \%$ CI, 0.67 to 0.94 ). While the results of the secondary prevention trials might have suggested a difference between dihydropyridine and nondihy- 
dropyridine calcium channel blockers, the risks of a first myocardial infarction associated with the three major subclasses of the short-acting calcium channel blockers in this study were similar Whether the long-acting formulations and other specific calcum channel blockers will have beneficial or adverse effects on the incldence of CVD remains to be seen. These questions require empiric evidence from additional studies.

In this case-control study, the use of calcium channel blockers, especially in high doses, was associated with an increased risk of myocardial infarction For calcrum channel blockers used in low doses (Figures 2 and 3), the association was small and close to 10 These findings provide indrect support to the fifth report of the

\section{References}

1 Joint National Committee on Detection, Evalua tion and Treatment of High Blood Pressure The fitth repor t of the Joint National Commitlee on Detection, Evaluation, and Treatment of High Blood Plessure (JNC V) Arch Intem Mod 1993,153154 18?

2 Siscovick DS, Raghunathan TL, Paaty BM, et al Diur etic therapy for hyper tension and the rusk of plimaly caldac driest $N$ Lingl I Mod 1994330 18521857

3 SHCP Cooperative Renearch Group Preven tion of stroke by antihy per tensive drug tratment in older persons with rolated systolic hyperten son final results of the Systolic Hyper tension in the I-klerly Program (SHCP) JAMA 1991,265 32553264

4 Merlical Resedrch C nungl Wor kung Purty Med cal Research Council tr lal of treatment of hyperten sion in older adults princ $1 p a$ l results BMI 1992,304 405412

5 Psaty BM, I unberg CD Tiediment trials mol bidity and mortality In $1 / \% \mathrm{JL} \mathrm{J}_{\mathrm{H}}$, Black $\mathrm{HP}$ Taubeit KA eds Hypertension Promen The Ls senhals of Hogh Blood Prossuc Ddllas,'Lex Amer 1 cdn Heart Association, 1993197201

6 Manolio TA, Cutlel JA, Гur ber g CD, Psaty BM, Whelton PK, Applegate WB Trends in phat maco $\log \mathrm{c}$ management of hypertension in the United States Auch Inkm Med 1995,155829 837

7 Psaty BM, Koepsell TD, Yanez ND, et al Tem poral patterns of antihyper tensive medhation use among older ddults, 19891992 an effect of major clinical tirals on clinical practice? IAMA 1995,273 14361438

8 Dahlof $\mathrm{B}$ Pcnnert $\mathrm{K}$ Hansson $\mathrm{L}$ Rcversal of left ventr cular hyper trophy in hypcr tenss e patient a metdanalysis of 109 ts ediment studies $\mathrm{Am} \mathrm{J} \mathrm{Hy}$ peiters 1992595110

9 Neaton JD, ( $x$ imm RH Jk, Prineas $R J$ et al, for the Treatment of Mild Hypcrtension Resedrch Group Treatment of Mild Hypcrtension Study (TOMHS) findlicsults /AMA 1993270713724

10 Beto JA Panual VK Quality of life in the trcat ment of hypertension a motadnalysis of clinical trals Am J Hyportems 19925192133

11 Held PH YusufS Tuberg CD ( alcium channol blockers in acute myocaldial infarction and unstable angma an over view BMJ 1989,2991187 1192

12 Yusuf S Held P, Iurberg ( Update of eflect of calcium antagonists 10 my ocardial infarction or angind in light of the scond Idnish Verapam Infaction Trial (DAVIT II) and other yeccnt stud les Am r Coudool 19916712951297

13 I urbeig CD Paty PM Myers JV Nitcolpine dose related inciease in mortality in patients with corondry hedrt disedsc Curulation In press
JNC, ${ }^{1}$ which recommends the use of lowdose therapy for all agents and the older proven antihypertensive drugs as preferred first-line agents However, when dureties and $\beta$-blockers are contrandicated, unacceptable, or not tolerated, ${ }^{1}$ calcuum channel blockers, ACE inhibitors, and $\alpha$-blockers remain mportant therdpeutic options for the control of high blood pressure.

Ongoing large-scale clmical trials will assess the effect of various antihypertensive therapres, including calcium channel blockers, on several important cardıovascular outcomes ${ }^{1421}$ Until these results are avallable, the findings of this study support the current gurdelines from the JNC, which recommend diuret$1 \mathrm{es}$ and $\beta$-blockers as first-line agents

14 The SOLVD Investigator s Fffect of enalapil on sur $1 \mathrm{v}_{\mathrm{c}} \mathrm{l}$ in patients $\mathrm{w}$ ith i crluced left ventriculds c]ection tractions and congentive heart falus $N$ Engl I Med 1991,325293,02 15 Pfefter MA, Bramuald F Moye LA, ct al Ef fect of captopr il on mor tality and morbirlity in jed tients with left ventriculdr dystunction aftex myo cardial infarction sesult of the Sur viral and Ven tricular Enlargement Tiral $N$ Lugl I Mad 1992, 327669677

16 Goldbourt R, Behal S, Relcher Riess H /son M, Mandelzwere I. Kaplinsky I, Ior the SIRIN'T Study Group Ear ly administiation of nitedipinc in suspected acutc myocas dial in larction the Second dry Pievention Rcinfar ction Isi acl Nifedipine 'T'r lal 2 Studv Aich Inkan Mod 19033153345353

17 Lichtlen PR, Hugenholt $P G$, Raffle nbeul W ct al Retadation of angiographe progicssion of colo naty ditery disease by niferlponc ro sults of the In ter national Nifedipine Tial on Antiatheroncler otic Ther apy (INTA( T) l ame ct 1900,3351109111) 18 Dahlof $\mathrm{B}, \mathrm{H}_{\text {cunsson }} \mathrm{L}$, Lindholm IJH, et al STOP Hypertension 2 a prospective intervention tricl of newer ver sus older trcalment dilci natuves m old pa tients with hypertension Swedish Tilal in Old Pa tients With Hypertension Blood Pass 19932136141 19 Amery A, Bir kenhager W, Bulputt CJ, et al SYS I CUR-a multcentre trid on the trediment of the ldterl systolic hype itension in the elder ly objectives protocol, and or gamiation Amm 1901,3,287302 20 Ihe NORDIL Groul) The Nor rle Inlliazem Study (NORDHL) a prospective inter vention tild of calcium antagonist thei disy in hy per tension Blowd Picss 1993,2;14 321

21 Dasus BR Cutler JA, Gordon I) I'urberg CD at al fot the AIJIIIAT Rcseduch (xlouj) Rational and clesign for the Antihyper tensve and Lipul Low ering J leatment to Picvent Hoal Atdack rial (ALLHA']) Am $I$ Higeilens In puens 221988 Jomt National Committe The 1948 ic por t of the Jornt National ( ommittec on I) te ction, Lvaluation, and 'T reatment of I I $1 \mathrm{gh}$ B Blood I'res sure Arh Intom Mad 1988 1451023103 2) Psaty BM, Heckbor t SR, Atkın ask of myocardial infarction associated with the combmed use of estrogen and joggcstins in pout menopdusal women $A$ ich Inton Mad 1994154 13331339

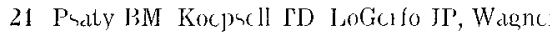

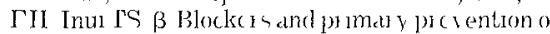
colondry heart diseate in patients with high blood pressure IAMA 1989,26120872094

25 Phaty BM, Kocpuell ID, Slacovick I) (t al An apporoach to acveral probleme on the une of latree databascs for population based case contu of stud unless they are contraindicated, unacceptable, or not tolerated

The reseach reportad in this atale was sup porter by grants HL40628 and HI 43201 from the National Heart Lung, and Blood Institute Di Paty is a Merck/Society tor Eprlemiological Resedrch Clmical Lpurtemology Tellow (rponsored by the Merck Co Foundation Rahway NI and the Society for Lpudermologic Resear ch Baltmore Mo

We apprecrite the comments crituclems, and suggestions that las A Manolio MD MIIS anonymous seviewcrs, and editors provided on

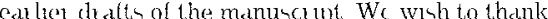

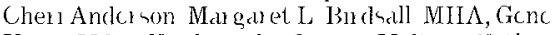
Ilat, Mike Hindmelsh, Gracle Melton Fither Normand Betty Monson Linda l'alec, ( hel yl Pur dic, Richard Schadalt Debor ah I imlin Mary Verd ery Jan Yec, and Pecsbala L Young PhD los the 17 help with this moject I hank too go to the

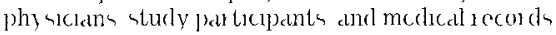
clerky at the Group Health c ooperative of Puget Sound

$x b$ of the therapeutic (llicacy and aafcty of ant hyper tenure molicines stat Med $19911065 ; 662$ 26 Paty BM, Koeprell ID, LoGal fo JP', Wagne $\mathrm{EH}$ Inui TS I he relative risk of myocaldal in farction in paticnt who have high blood pressurc

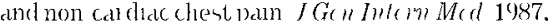
2381387

27 Scucuter (S Dombek CI Olm BR Kastrup

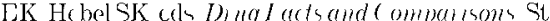
Ioux Mo I acte and (ompar lsone 1994

29 Schlcuselman J o ase (ombolsluders Desegu Comduel Aurelases Nou York NY Oxforel Unu versity Pjous 1082

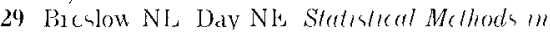

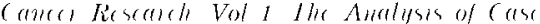
comtiol sludics Lyon I sance Internatuonal Agcncy for Reacall on (ancer 1990 IAliC Sol entific Publications No 32

30) Rohlfing J J Bi un/ell JI) The c ffects of diul et tce and adrenergic blocking age nts on plabma lip lils Wrat J Mod 1980,145210219

31 Mcclellan K Unexpected reurlts from MIDAS

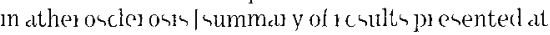
the 15th scientific Mecting of the Internatiotsd? Socret of Hyper tension in Melboum nc Australlal, March 1994l Imphamare Whly 19949324

32 Terguson JJ Momomuias Highlight fiom the 58 th annulal actcrific mocting of the Japanese (11culation Socrety ( nc ulakon 19949021942196 33 I mbag (O), Bymeton RP' Bor ham NA for the MII)A \& Resear ch Group Multicenter I br arlipme Diurctic Atheroncleroms Sturly (MIDAS) desenn features Am I Mod 194986(suppl 4A) 37 ;9 if Wagenknecht I I ukbere ( D, Hammon J Legault ( 7roost. I Surgeal blecdine an uno pected effect of calcium ant igonests? $P S M J 1995$, 310776,777

35 Lestrup K, Anderan P'L Iransicnt myocal

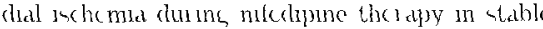
aneind pecior in and ite relation to coronal y collat (adl flow and comparison with metoprolol Am $J$ (a)deol 100) 71177 18?

36 Rurcka M Iaconen I HH Riclevance of mics mottent incredses in sympathetic activity lol ad vascoulcome on shor t actine calcium antagonists

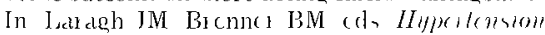

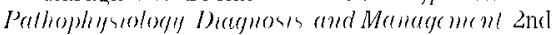
al Now Yonk NY Relven Prese 199528152925 37 Muller JL Iofles ( ${ }_{x} \mathrm{H}$ Stone PII (ncadean valdion and treger in of onact of acute c 11 diovas culat discase (nollatiom 198979733743

38 IIIlk eass WI3 Ohman TM I c mborger JD ( a

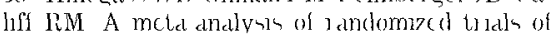

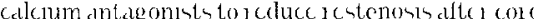
naty angloplemt Am I (ardnd 199473535439 